Changes in immigrant individuals' language attitudes through contact with Catalan: The mirror effect.

Montserrat Cortès-Coloméa ${ }^{*}$, Mònica Barrieras ${ }^{\mathrm{b}}$, Pere Comellas

${ }^{a}$ Department of Cognition, Development and Educational Psychology, Universitat de Barcelona, Passeig de la Vall d'Hebron 171, Barcelona 08035

${ }^{b}$ Department of General Linguistics, Universitat de Barcelona, Gran Via 585, Barcelona 08007

'Department of Romance Philology, Universitat de Barcelona, Gran Via 585, Barcelona 08007

*Email: mcortes@ub.edu /*Telephone number: 933125139 


\title{
Changes in immigrant individuals' language attitudes through contact with Catalan: The mirror effect.
}

\author{
This paper presents the results of a study based on the change in language \\ attitudes experienced by some allochthonous individuals through contact with the \\ sociolinguistic situation in Catalonia. Previous studies (Junyent et al., 2011) have \\ suggested that in some cases, contact with Catalan -a minority language with a \\ valued identity- acts as a stimulus for some foreigners to re-evaluate their own \\ linguistic heritage. The present ethnographic research aims at providing some \\ clues as to how the discovery of a minority language triggers changes in \\ representations and attitudes. The study employed a qualitative methodology \\ based on in-depth open interviews. The narratives analysed reveal various socio- \\ cognitive mechanisms. The informants report having initially experienced the \\ autochthonous minority language as an obstacle but later on developed an \\ alliance with it and with minority languages in general. This change seems to be \\ influenced by positive affective socialization experiences in the host society and \\ by the growing perception that knowing the language makes them members of \\ the community. Furthermore, the sociolinguistic situation is perceived as an \\ alternative model for rethinking one's own language ideology. As a result, a \\ mirror effect, or movements of reciprocity, emerges as the representation built in \\ Catalonia is projected onto the homeland.
}

Keywords: language attitudes; language awareness; language ideology; metalinguistic awareness; sociolinguistic awareness; metacognitive awareness.

\section{Introduction}

Many studies have examined the communication barriers between culturally and linguistically different groups. Field research has often stressed the difficulties in groups' mutual adaptation and emphasised the linguistic and cultural barriers that often lead to negative emotions and attitudes and, as a consequence, difficulties in understanding (Fishman, 1972; Gardner and Lambert, 1972; Pütz, 1994; Stephan and Stephan, 1996). In these situations, a gradual desertion of one's own language in favour of the majority or hegemonic language has often been reported (Edwards, 1992; 
Grenoble and Whaley, 1998; Nettle and Romaine, 2000; Sasse, 1992). Our study focuses on a fairly different picture. We aimed to examine how in some cases, contact with a minority language acts as a stimulus for some foreigners to re-evaluate their own cultural and linguistic heritage or even to reinterpret their language origins.

Previous studies (Junyent et al., 2011) have suggested that contact with Catalan sometimes prompted a shift in language ideology. While conducting an inventory of the languages spoken in Catalonia (Barrieras and Monrós, 2005), we contacted some alloglots, or individuals who speak a language other than Spanish or Catalan, who had adopted Catalan as their social language and, moreover, had reconceptualised their own language legacy. Whether they were speakers of a minority language or not, these individuals had reinterpreted their own attitudes towards minority languages, had reassessed their linguistic heritage, and had developed interest in linguistic diversity in general.

Catalan is the autochthonous language of Catalonia, a nation that has hosted several different waves of immigration over the past century. The first wave (in the 1970s) came from Spain. The vast majority of immigrants were Spanish monolinguals. Currently, approximately 55\% of the population over 15 years of age still have Spanish as their initial language (Institut d'Estadística de Catalunya, 2013). This means that Catalan shares social uses with Spanish. Moreover, Spanish is a co-official language along with Catalan. The second wave of immigration came as a result of the migration phenomenon produced worldwide at the end of the twentieth century. Discounting immigration from Latin America, currently 7\% of the population has neither Catalan nor Spanish as their initial language. Appendix 1 offers some sociolinguistic data to provide a more precise picture of the current situation of Catalan and Spanish in Catalonia among the population over the age of 15 . 
Although in sociolinguistic terms, Spanish is the hegemonic language -that is, the taken-for-granted language because it is the official language of the country-, contact with Catalan seems to have fostered in some alloglots a change in linguistic representation. Although some research (Huguet and Janés, 2008; Lasagabaster, 2003; Lasagabaster and Huguet, 2007) has analysed language attitudes towards minority languages in Spain, including Catalan, the phenomenon outlined remains unexplored. Thus, the present ethnographic study aims to uncover some clues to the mechanisms behind it. How does the discovery of a minority language trigger a change in language ideologies, attitudes and even behaviour in some individuals?

Following Silverstein, the concept of language ideologies can be understood in terms of the 'sets of beliefs about language articulated by users as a rationalization or justification of perceived language structure and use' (1979, cited in Kroskrity, 2004, p. 497). These beliefs emerge through the sociocultural experience of the speaker. Language ideologies structure peoples’ perceptions and enable a certain understanding of the world, either explicitly or implicitly. As Kroskrity (2004) noted, rationalization as a dimension of language ideologies is a first step towards changing them.

However, ideologies do not only obey rational reasoning. As attitudes, they also involve an influential affective component. Affect has its roots within the socialization processes in which it is discursively constructed (Besnier, 1990; Ochs, 1996; Ochs and Schieffelin, 1989). Every time a speaker is involved in a social interaction, the affective dimension is present. According to Ochs, 'affect is richly indexed in all languages of the world' (1996, p. 411). The very expression of an ideology is intertwined with an affective stance towards such ideology.

Ideology and affect drive speakers to act in accordance with their cognition and evaluations. Language attitudes influence people’s behaviour (Fishman, 1972; Gal, 
1978; Kroskrity, 2004). Nevertheless, studies on language ideologies and attitudes note that their relationship with changes in behaviour is complex. Language ideologies and representations are beliefs about the speakers' languages that in turn shape individual attitudes, and attitudes are related, at least to some degree, to behaviour (Gardner, 1985). Although it is true that behaviour can conceal true attitudes, in the middle or long term, attitudes are predictors of behaviour (Baker, 1992; for a review, see Bohner and Dickel, 2011, and Glasman and Albarracín, 2006). Likewise, it has been noted that changes in attitudes and behaviour are related to the quantity and quality of social exchanges (Spencer-Rodgers and McGovern, 2002). Social experiences awaken positive feelings, generate interest and respect for the other and even, in certain cases, trigger wholesale identification with the other (Gardner, 1985). In short, social relations are a key factor in the formation of attitudes. Still, Spencer-Rodgers and McGovern temper this idea by claiming that what the social setting fosters is a reduction in prejudices and that it has an effect on the emotions as well. Thus, as changes in attitude are subsidiary to emotional changes, it is not so much a question of prompting frequent social relations as it is about fostering exchanges that generate positive affectivity.

A key factor to changing linguistic representations is facilitating the creation of mechanisms of intersubjectivity that allow a world of socially shared meanings. In this sense, language is crucially important, not so much as a mediator of communication exchanges but as a basic instrument of social interaction. Social interaction is a key instrument for maintaining communicative exchanges; at the same time, it enables individuals to access and master the instrument itself. The underlying idea is that whatever is experienced in social interactions has individual repercussions -a concept known as semiotic mediation - that make it easier to understand other realities, i.e., it enables individuals to access new mental perspectives (Bruner, 1990; Wertsch, 1985). 
For this reason, social interaction and language are two inextricable realities that together help to gradually construct systems of shared meanings.

On the other hand, on an intrapersonal level, as Kramsch (2006) claimed, language generates subjectivities. Language is not solely code but also a system for the construction of meanings that define and identify people. As such, it is a key element in their subjectivity. Research has stressed that command of the language is related to attitudes (Baker, 1992; Huguet and Janés, 2008). Nevertheless, the way people experience language is as important as any formal knowledge they may have. Language is not a construct devoid of motivation but a cognitively and emotionally internalised reality. As Bruner (1996) has noted, what people do is never done by chance; rather, their actions reflect beliefs, desires, values and other intentional cognitive states.

Related to ideology is the concept of identity. Language ideologies are directly linked with the creation of social and cultural identity. According to Bucholtz and Hall, ‘identity is created through language and other semiotic systems’ (2004, p. 383). From this viewpoint, just as the formation of subjectivities is socioculturally mediated and driven through language use and social interaction, the same is true for identities.

From an essentialist stance, identity has been viewed as categorial; that is, a social group includes those who are like one another but different from members of other groups. Sociological and anthropological studies on identity have focused on relations of agency and power. In this case, sameness and distinction have a sociopolitical end. Minority groups emphasise their differences from hegemonic groups as a strategy to halt assimilation. At the same time, in-group likeness is reinforced. Within this framework, language practices are means of marking and maintaining identities. This is the case for many minority language communities whose social identities are 
said to be constructed contrastively (e.g., Eckert, 1983 for Gascon Occitan; Jaffe, 1999 for Corsican; Timm, 2001 for Breton L1 versus L2 speakers).

Yet, the relationship between sameness and distinction is not necessarily dichotomous. The phenomenon of identity is much more complex, varied as well as context-bounded. It emerges 'as a product of situated social action, identities may shift and recombine to meet new circumstances’ (Bucholtz and Hall, 2004, p. 376). We started this study because we found that some immigrants identified with Catalan without abandoning their original identity. At first glance, it looked as if contact with a minority language had prompted a change of linguistic representations. Yet, this is not a widespread phenomenon. In the large cities of Catalonia, immigrant adults mainly learn to speak Spanish. They can live in Catalonia without speaking Catalan or even without understanding it. What circumstances, then, lead individuals to identify with a minoritized language? A minoritized language refers to a language "whose value is not recognized on the interactional scene by speakers of a sociolinguistically dominant language” (Kasbarian, 1997: 188). We thus wondered about the mechanisms that lead individuals to change their language attitudes and even their attitudes towards their home minority languages and linguistic diversity in general.

Some authors (Fishman, 1999; Kroskrity, 2004; Woolard, 2008) have emphasized that the global economy and international communication have made identities less culturally heterogeneous and not so tightly territorialized. Simultaneously, some local vernacular languages have experienced a resurgence. Faced with the threat of globalization, a sense of belonging to local communities has sparked and encouraged the revival of minority languages. Local languages are seen as a mark of authenticity and function as distinctive symbols. 
Authenticity has been opposed to anonymity as two antagonistic ideologies (Woolard, 2008). The ideology of authenticity is associated with non-hegemonic and local languages. For a language to be authentic, it must be rooted in a social and geographic territory. In semiotic terms, it has the pragmatic function of social indexicality. Authentic speech signals who you are. Furthermore, it forges the essence of the individual. In this sense, authenticity implies valued identity. On the other hand, the ideology of anonymity is related to a general voice that belongs to all and to no one in particular. It is disembodied, 'from nowhere'; thus, it is idealized as public, objective, rational, universal and true. Anonymous languages belong to all and can be used by all. As a result, they are in a superordinate position and therefore in a position of dominance. This is how these languages become hegemonic.

On the one hand, the ideology of authenticity still gives Catalan a valued identity; on the other, Catalan has been regarded as a clear case of successful language revitalisation. In this scenario, it is plausible to think that some foreigners may find in the Catalan situation a mirror that makes them 'discover' the minority languages of their countries of origin or reconceptualise their own language, in the case of speakers of minority and subordinate languages. It is also likely that foreigners may see multilingualism as beneficial in practice, as it allows them to maintain their own language and simultaneously maintain 'authentic' social relationships in the local setting.

Thus, our study deals with the alliance some individuals forge with a minority language (in this case Catalan), an alliance that causes them to reinterpret their own linguistic heritage. This reinterpretation leads them, in turn, to become advocates for minority languages in general. We aim at a deeper examination of this little-known phenomenon which we call the mirror effect - a term that alludes to the 
reconceptualization of one's own language or the sociolinguistic status of home minority languages based on experience with another minority language. Our aim is to better understand some of the clues explaining how the discovery of a minority language triggers these changes in linguistic representations and even behaviour.

We shall use narrative analysis to interpret the socio-cognitive mechanisms that may have fostered this phenomenon and to better understand the mechanisms of reciprocity that have been generated.

\section{Methodology}

The sample included some of the individuals that we had come across in our field research while cataloguing the languages spoken in Catalonia (Barrieras and Monrós, 2005). As we were interested in identifying factors that foster a change in representations, the sample does not aim to be representative of all alloglots in Catalonia. It was initially conceived as an ethnographic study with the aim of exploring the aforementioned phenomenon. The subjects were chosen based on previous conversations in which they had articulated a language ideology favourable to diversity and preservation. The final sample consisted of 13 participants, as some of the original informants could not be contacted.

All subjects were aged 21 to 47 . All of them had migrated from other countries and had different initial languages. In addition to their mother tongue, some had learned a second language as children -this is the case of participants whose mother tongue is a minority language in their country of origin- and most of them are competent in other languages in addition to having a good command of Catalan and Spanish. They belonged to a medium-low and medium-high socio-professional status, and most of them (11 out of 13) had completed tertiary education. Their main motivations for moving to Catalonia were employment, followed by various family reasons. Their 
length of stay was diverse; 5 of them had stayed in Catalonia for fewer than 5 years and only 2 had stayed for more than 10 years. In short, the only variables that participants had in common were a high educational level, an interest in preserving minority languages (expressed in different ways and to varying degrees, ranging from cultural activism to academic work on the subject), and their taking as a reference the Catalan sociolinguistic situation and its revitalization project. Table 1 shows the general profile of informants.

[insert Table 1 near here]

The participants were all interviewed once and individually. The interviews were semi-structured, based on open-ended survey questions (see Appendix 2). Data were complemented by additional questions that, in the judgment of the interviewer, allowed him or her to dig for further information on the issues that the informants themselves brought up. In this way, narratives emerged in which our informants' feelings, beliefs and attitudes came into view naturally.

The interviews were held in settings familiar to the subjects. The interviews were audio-taped and transcribed by the research group. Given that the sample is small and that subjects were non-randomly selected, data analysis is qualitative in nature. We first generated a thematic coding scheme from 3 pilot interviews. Those ideas mentioned only once in the narratives were omitted. Next, we identified the most salient and recurrent concepts. Table 2 describes the final coding schema. [insert Table 2 near here]

\section{Results}

We collapsed the expressed concepts into five major topics that were content-related. 
All informants referred to the five themes identified although not all of them mentioned all the subtopics. That is, there is some variability in the frequency of subtopics mentioned. The subtopics most frequently mentioned were: (a) public visibility of Catalan (since most informants expected low public uses of the minority language); (b) initial perception of Catalan as an obstacle and initial reluctance to use the minority language; (c) autochthonous shift to the dominant language when addressing foreigners which (d) generates a feeling of exclusion; and, finally, as expected given the selection of participants, we found a high frequency of mention of the subtopics included in categories 4 and 5. Below we outline the five major points detected, illustrated by excerpts from the interviews.

\section{Prior expectations: Catalan language as an obstacle}

Many of our informants stressed that, before coming to Catalonia, they had some awareness of the existence of Catalan. However, this knowledge was quite diverse, from a simple, imprecise mention of the existence of another language in addition to Spanish to rather detailed information.

Only two of our interviewees said they had adapted to the Catalan language situation from the very beginning. This is the case for those who came from Senegal and were native speakers of Wolof and Fula. They claimed that knowing a language from the same family -French- had helped them to understand Catalan. They also noted that they were in regular contact with other minority languages in their home country.

Other informants admitted to having had a 'theoretical' understanding of Catalan. On arrival, they were surprised by the visibility of this language, as our Polish (1) informant told us. 
(1) What really surprised me was that, yes, it wasn't just a fairy-tale when they say it's a minority language, a stateless language; rather you can hear it on the streets and it was prestigious, all the history, literature, film... It was quite fascinating.

These words conceal prototypical ideological expectations regarding minority languages: they are conceptualized as being non-public, non-literate and local, with no media outlets. However, Catalan is used in the public spheres; it has a long literary tradition and is used in schools and universities.

Nevertheless, Catalan is sometimes not accessible to many immigrants. One of the best known and described sociological phenomena is the tendency for immigrants to congregate together. They mostly live in the suburbs of the cities, where the Catalan language has little presence. Instead, there is a high number of Spanish-speaking people. Thus, Catalan can be somewhat invisible to a major sector of the foreign population. Either due to limited contact with Catalan or through processes of identification with the majority language, some interviewees reported they had been misinformed by their relatives or friends already established in Catalonia. In these cases, the image they had before arriving was biased. This is what our Tamazight (2) informant told us:

(2) They [my siblings] knew that part of the population here speaks a language other than Spanish, but they thought it was very few people. [...] They knew a few words, like adéu (good-bye), si us plau (please) and nothing else [...].

Having some previous knowledge of the existence of Catalan does not prevent the language from initially being viewed as an obstacle instead of an opportunity. Even the allochthonous people who speak minority languages admitted to an initial reluctance 
to adopt Catalan, as illustrated by the excerpt from our Chilean informant, who also speaks Mapuche-Mapudungun (3).

(3) When I arrived in Catalonia and discovered that there was a language other than what you thought would be your shared language here, I was astonished. [...] It was hard for me to understand the situation because it poses a difficulty when you arrive here and you think that you can keep operating in your own language.

Most of our informants said they had rejected learning Catalan at first.

Undoubtedly, in a sociolinguistic situation like Catalan, immigrants face a double effort: they must learn Catalan and Spanish. They often choose the hegemonic language because they know that local people understand them anyway. This attitude is frequent among those that speak another hegemonic language.

The narratives show that, at first, erasure of the Catalan language is often a common process among our alloglot informants. Their position as social actors shows the ideological influence of the hegemonic model — there is a 'natural' language which corresponds to the state language. In fact, the bi-univocal identification of state and language is a widespread stereotype. This might explain why the minority language is often perceived as an obstacle. The first cognitive resource consists of interpreting the new situation based on the previous schema from home. Speakers of official and prestige varieties tend to identify Catalan with the stigmatised, minority languages in their homeland.

\section{Linguistic behaviour of autochthonous individuals and accommodation norm}

One of the most recurring features in our informants' reports is that autochthonous people speak to them in Spanish, which hinders them from living their lives in Catalan, as a Wolof speaker (4) tells us: 
(4) Interviewer: In what language do the people from here speak to you?

Informant: In Spanish, always, always. That always happens. Even when you answer them in Catalan, they keep speaking Spanish. [...] They don’t realise it. Many of them are not even aware of it.

The identification of an individual as allochthonous seems to transform the linguistic behaviour of Catalans, even when their counterpart has no physical features that give them away as foreign.

This code switch to Spanish on the part of autochthonous people harbours an assumption: immigrants will choose Spanish as their social language, as is extensively described in the Catalan sociolinguistic literature (Vila and Galindo, 2012). The Wolof informant clearly expressed this presupposition from the mouth of a local: If you're not from here, surely you speak Spanish. [...] That's the rule. The strength of this assumption even goes so far as 'translating them', as the informant from Kazakhstan says in excerpt (5). The fact that the alloglot breaks the 'rule' triggers surprise among Catalan speakers, as reported by the Chinese informant who was told Oh, you speak Catalan? How delightful! Even autochthonous people who express highly positive representations of the fact that their allochthonous counterparts adopt Catalan take for granted that alloglots will use Spanish.

(5) My husband is Catalan and I've always spoken Catalan to my husband's family and our children. Even so, my father-in-law always spoke to me in Spanish. Even when he quoted me he did it in Spanish, even though I had just said the same thing in Catalan.

As a result, the allochthonous person tends to accommodate to the language used by the autochthonous person. The empathetic and intersubjective processes that arise in 
communicative interchanges can explain why speakers feel the need to share the same code. When Catalan is not a person's initial language, it is very difficult to continue using it when the Catalan interlocutor does not. This is what is illustrated in the excerpt below from the interview with one Russian informant (6):

(6) [...] I imagine he saw my surname and changed languages. [...] I tried to keep speaking Catalan, but since he didn't answer me I didn’t want to push it because that creates a situation; if I insist on speaking Catalan and they answer me in Spanish, it's a bit unequal.

The factors we have identified show that the Catalan-speakers' representations

fit the ones described in other cases of subordinate languages. McEwan-Fujita (2010) reports reluctance of Scottish Gaelic native speakers to engage with L2 learners through the medium of Gaelic. The same phenomenon has been described by other researchers (MacCaluim, 2007, for Scottish Gaelic speakers, cited in McEwan-Fujita, 2010; Newcombe, 2007, for Welsh speakers in Wales). The choice of a language in a particular situation entails an identification strategy with the social categories and activities that the language symbolizes (Gal, 1978). In some situations, like the ones we described above, the choice of a language implicitly involves a categorization between 'locals' versus 'foreigners'. In this case, the accommodation norm² dictates that Catalan speakers have to speak Spanish to 'foreigners' or in their presence to be polite and supportive (Boix, 1993; Woolard, 1989). This behaviour denotes an underlying set of beliefs in which Spanish occupies a hierarchically superior status. These social practices may help to reinforce the concept of Spanish as the default language.

\section{Perception of exclusion: language as a hallmark of identity}

Autochthonous language change is experienced as discriminatory and exclusionary. The 
expression of this feeling is an indicator of the belief that Catalan speakers' refusal to speak to them in Catalan strips the foreigners of access to Catalan. As a result, it deprives them of the right to be recognised as members of the community. Excerpt (7) extracted from the interview with the Bulgarian informant is quite clear on this matter.

(7) My husband and I came from Bulgaria several years ago and our children were born here. We speak to them in Catalan and usually everyone speaks to us in Catalan. However, when I have to show my documentation and they see that I'm Bulgarian, they speak to me in Spanish even though we had been speaking Catalan until then. This happens at the doctor's office in particular. One day, my son asked me why doctors didn’t know Catalan. And this makes me feel very bad.

Excluding means failing to recognise the other, and as a result, it means promoting rejection and the construction of opposing othernesses. It also affects people's self-esteem and self-image, which proves to be an enormous barrier to constructing a cohesive community. In contrast, our informants perceive that speaking Catalan makes them members of the community. In the terms of one Russian informant, knowing the language gives you power. One common feature of the narratives analysed is that language is a key factor in group belonging and confers identity. We found many examples of this within the narratives: Doors open for you if you speak Catalan; You feel like you can do the same things as other people; In my opinion, you have to speak this language to integrate; I observed that I was part of a community.

Giving a language an identity value signals a metacognitive reflection in which the concepts of language, identity and integration are associated. The informant who said I see that many people here are integrating successfully, referring to his 
compatriots who are learning Catalan, tells us that language is a key part of feeling integrated.

At the same time, our informants stressed that the use of Catalan facilitates the maintenance of social and personal relationships. Moreover, they reported positive affective socialization experiences, which in turn encouraged them to continue to use Catalan. You go to the greengrocer's and speak Catalan and he'll give you the best apples. It's like, I don't know, extra points, as reported by our Fula interviewee.

Therefore, our informants confirmed that the language variable is crucial in the construction of identities and ascription to a symbolic universe. Languages are not only means of expression; they are simultaneously instruments that represent constructs of reality and provide their speakers with a shared framework of references. Thus, more than merely speaking Catalan, adopting it means identifying with the group and becoming part of the culture of the language spoken.

\section{Mirroring and movements of reciprocity}

Knowledge of the linguistic situation in Catalonia acts as a mechanism of identification with the minority group. In other words, people who had replaced their family language with the dominant language in their homeland feel the need to revive their lost legacy and question the supposed advantages of language shift. Such is the case with the informants whose native tongues are Quechua (8) and Wolof (9), respectively:

(8) Somehow what is happening here has led us to see what is happening there, and if it weren’t for contact with Catalan I might have never thought about it.

(9) I think you can see the influence; there are many Wolof people here who are now aware of defending their mother tongue. 
Thus, not only may knowledge of the linguistic situation in Catalonia generate processes of reinterpretation of their own situation; it may also even create a mirror effect. Earlier in this paper we said that most of our interviewees initially saw the Catalan language as an obstacle. Later, a change in language ideologies is observed. Moreover, the representation built in Catalonia is projected onto the homeland and inspires a kind of solidarity amongst dominated individuals. Movements of reciprocity emerge, as observed in the excerpt below (10) from the Kazakhstan informant.

(10) I think that I had this interest in speaking my language [...] after I took the intermediate level of Catalan. [...] The more Catalan I speak, the more Tartar I feel. I have this feeling that now I have to study Tartar.

Reinterpreting what language shift entails seems to be a metacognitive step, especially among allochthonous individuals whose initial language is also minority but continues to be used in families and transmitted intergenerationally. Two excerpts from our Tamazight (11) and Wolof (12) informants clearly state the idea that the situation of Catalan in Catalonia can function as a role model for their native community.

(11) I discovered the resemblances between Catalan and Tamazight and that helped me to clearly understand the reality in Catalonia and that I must respect this reality and the attitude I should have towards my children and my environs. [...] One thing reinforces the other. Discovering the differential features of Catalan reinforces my desire to fight for the uniqueness of Tamazight.

(12) If the Catalans are standing up for themselves, [...] are making this effort, why can't I? [...] How can it be that we have come to express ourselves now in French, now in Catalan, yet we can’t do it in our mother tongue? Those are things that if other people fight to get them back, I could, too. 
Overall, contact with the sociolinguistic reality of Catalonia has made our allochthonous informants aware of the processes of minoritization and the pressures that major languages exert on minor ones. In certain cases, especially if there is prior awareness of one's own language variety as subordinate, what takes place is a reconsideration of one's attitude and representations in terms of the possible status of these minoritized languages. Catalan is perceived as a minoritized language -and it is compared with their own minoritized language. Yet, it is also regarded as a language that plays roles that are usually reserved for dominant languages. This triggers a revision of assumptions about the possibilities of their own language. What they were aware of, i.e., linguistic subordination, which was before regarded as inevitable, necessary and impossible to change, is now questioned.

\section{Changes in language ideologies}

Our interviewees changed their ideas of how a community should be organised in linguistic terms. Now, our informants go a step further and view the existence of different varieties positively. Increasing respect for one's own tradition spreads to other languages. This is how the Fula (13) participant expressed the idea:

(13) I think that language is very important because it is a part of culture. [...] And a language is not something that can be created in ten or twenty years; it is something that takes years [...]. So I don't want languages to lose their value, any language.

Even the informants whose initial language is dominant show a positive discourse about language learning. The minority language is not yet seen as an obstacle, but as something gained, in the words of the Chilean interviewed. The acquisition of a new variety is experienced not as a replacement but as an addition, a source of 
enrichment that should not cast doubt on previous linguistic knowledge, as the Siberian (14) informant expresses:

(14) I guess promoting the use of a language in all spheres [...], if you can keep the balance between Russian and the minority language, we all come out ahead.

The conceptualization underlying We all come out ahead illustrates the attitude that our informants have developed. Their enactment in favour of the unfolding of minority languages is clearly stated in various passages. For example, the Fula informant claimed to have Learnt so much about Catalan, with its society, its culture and its way of defending Catalan; it is a style that would be perfect for my country. Meanwhile, the Chilean asserts that A lot can be done for Mapuche culture, in this case, from Catalonia. Similarly, the Chinese (15) interviewee calls for recognition of different linguistic varieties in China. Though official linguistic ideology in China has traditionally been monolinguistic to an extreme, the informant openly questioned this situation.

(15) I would like the status of many of the Chinese languages or dialects that are now considered only dialects to be truly recognised, so they can be considered true languages. I would like them to become languages and I would like their development, cultivation and transmission to future generations to be encouraged.

The Tamazight speaker is actively engaged in an organisation to promote the Amazigh language and culture in Catalonia. Likewise, the Fula informant takes part in projects to promote the Catalan language as a way to feel closer to his roots. Two final paradigmatic cases are those of the Russian and Polish interviewees. The Russian became involved in the study and research of the Tartar language, which was the initial 
language of her ancestors. In the same vein, the Polish (16) informant reported that her contact with the situation in Catalonia has changed her overall conceptualization of languages and has prompted her to investigate the Kaszuby language.

(16) When I came here, what I had studied at the Socialist school was what I knew about the linguistic situation. So I had a picture that Poland was a country with a single language and that there were some immigrant languages, but, well, they were the languages of people who came from consolidated states. They weren't minority languages; we had no concept of that.

On the whole, our interviewees move away from the established norm. In language, they replace the ideology of homogenization with the ideology of heterogeneity. It seems that the sociolinguistic status of Catalan triggers in some individuals a change in language ideologies and attitudes.

\section{Conclusions}

This study was conceived as ethnographic research with the aim to explore the beliefs and attitudes of allochthonous individuals who had experienced a shift in their linguistic representations through contact with Catalan. In Catalonia, Catalan shares social uses with Spanish, which is the hegemonic language. Thus, we aimed to grasp how the discovery of a minority language leads some individuals to modify their attitudes and ideologies and develop an alliance with the minority language, and in turn, with minority languages in general. For this purpose, we interviewed thirteen immigrant individuals from different origins and backgrounds. The analyses were carried out from an open-ended questionnaire and are qualitative in nature.

The first aspect that most informants stressed was an initial reluctance to learn Catalan. At this stage, the linguistic representations from home are usually projected 
onto the new situation. Spanish is the taken-for-granted language. Thus, Catalan is seen as an obstacle. This ideological process of erasure (Irvine and Gall, 2000) renders Catalan invisible.

Still, our interviewees over time identified themselves with Catalan and adopted it as the commonly used language without, however, abandoning their initial language. Language ideologies emerge from social experience and influence peoples’ perceptions (Kroskrity, 2004). Language can be viewed as a barrier or opportunity and the choice has an influence on attitudes. In our study, the interviewees’ engagement in communication practice in Catalan develops complicities with Catalan speakers. Hence, the alloglots studied developed positive affective stances towards the local language. Certainly, the way people experience language plays a key role in the creation of intersubjectivities. As numerous studies have found, fostering quality social contacts stimulates positive feelings and helps to replace the negative perception of what is different (Spencer-Rodgers and McGovern, 2002).

In discussions of the value of language, Woolard (2008) distinguished between anonymous and authentic ideologies. Catalan was placed in the second group as it is not hegemonic, is non-neutral, and is still closely tied to identity. The narratives analysed show that interviewees associated the use of the Catalan language with group belonging. They explicitly complained about locals' language switch with foreigners, which is experienced as a discriminatory, exclusionary act.

The sociolinguistic situation in Catalonia becomes perceived as an alternative model for rethinking one’s own language ideology and linguistic identity. Allochtonous individuals revalue their heritage language and even become advocates of linguistic diversity in general. This change seems influenced by a more intense relationship with 
the Catalan community and by the growing perception that language is a key part of feeling integrated.

Catalan is a minoritized language, yet it has a rather unique sociolinguistic situation, given that it plays a relatively important role in public discourse. From this standpoint, it may become a model for other minoritized languages whose status is more precarious. The possibility that a language identified as minoritized can access certain realms that seemed to be reserved exclusively for hegemonic languages may trigger a change in language ideology.

This study suggests that languages with a capacity to create identity, like Catalan, become key factors in both integrating into a new community and valuing one’s own cultural and linguistic heritage. We labelled this phenomenon as the mirror effect. It refers to a process whereby the more we identify with the host culture, the closer we feel to our own roots. Thus, a new scenario emerges that allows integration without the replacement of one identity by another. This representation of identities is not dichotomous and opposing, but mutually reinforcing. In this sense, it looks like a process of inventing similarity by downplaying differences (Bucholtz and Hall, 2004). From a semiotic perspective, language is a crucial factor in constructing identities. Given that Catalan is a minoritized language, a hierarchical relationship of power between languages would not be established. Therefore, in this context, differences can be set aside whilst similarities can be highlighted.

According to Silverstein, speakers can take a step forward and change their language when they rationalize it (1979, cited in Kroskrity, 2004). This reasoning can be extended to ideologies. In the same vein, Kroskrity (2004) highlights consciousness as one of the dimensions of ideology. He suggests 'a correlational relationship between high levels of discursive consciousness and active, salient contestation of ideologies 
and, by contrast, the correlation of practical consciousness with relatively unchallenged, highly naturalized, and definitively dominant ideologies’ (Kroskrity, 2004, p. 505). Our data point in the same direction. Initial reluctance towards the minority language, which we related to practical consciousness, shifts into an alignment with it. Interviewees end up with a high level of awareness of language ideologies. This would allow them to actively choose an 'authentic' ideology instead of a dominant one. Our informants seem to perceive that choice of the new ideology eases social relationships and gives them an identity without compromising the original one.

Finally, the emergence of a metacognitive consciousness evolves into favourable attitudes towards linguistic diversity in general. Some of our interviewees became involved in various language revitalization activities.

Undoubtedly, this study has to be extended and more data are needed. Firstly, the methodology has to be further reinforced. As a qualitative study, it cannot account for the precise mechanisms that lead individuals to change their language attitudes. Certainly, there is a gap between learning a minority language and reinterpreting one's own linguistic heritage. Still, this survey offers some hints regarding what mechanisms might explain this process. Further research should shed more light on the factors identified here, and moreover, other factors might emerge. Is the immigrant's mother tongue related to changing language attitudes? Our participants have different initial languages, some of them hegemonic. However, a few of them have a minority language as their mother tongue. An increase in the number of participants should shed light on the relative importance of this factor, an issue that this survey cannot answer as the sample is small. Finally, it should be noted that our interviewees are not representative of the whole immigrant community in Catalonia. 
The phenomenon outlined in the present study could be exported to related or similar contexts either in Spain (e.g., the Valencian Community or the Basque Autonomous Community) or in other European regions (e.g., Friesland, Malta or Wales). On the one hand, many minority languages are threatened and, on the other, bilingualism (and multilingualism) is the norm, not the exception. We believe that this phenomenon should make us reflect on linguistic and social dynamics in current multilingual societies to try to find other means of integration that could be more effective and respectful of individuals' linguistic and cultural identity beyond simple tolerance or denial. Awareness of this phenomenon seems to us particularly relevant in suggesting models of peaceful coexistence without sacrificing diversity, in designing integration policies and, more generally, in the processes of revitalising minority languages.

\section{Acknowledgements}

This work was supported by the Agència de Gestió d’Ajuts Universitaris i de Recerca (AGAUR, Agency for Management of University and Research Grants) of the Generalitat de Catalunya (the Catalan government) under Grant ARAFI-2007; and from Spain’s Ministerio de Ciencia e Innovación (Spanish Ministry of Science and Innovation), under Grant FFI 200909955. Our thanks M. Carme Junyent, Eva Monrós and Mònica Fidalgo for their collaboration on the project. Also our deep appreciation to all participants and xxxxxx. Finally, two anonymous reviewers and the editors provided helpful and detailed comments on earlier versions of this paper.

\section{Notes}

1. All the subjects in the study speak both Catalan and Spanish in addition to the languages listed above.

2. The phenomenon referred to here has also been termed the 'courtesy rule' (Coleman, 1975, cited in McEwan-Fujita, 2010). 


\section{Notes on contributors}

Montserrat Cortès-Colomé, Mònica Barrieras and Pere Comellas belong to the Grup d'Estudi de Llengües Amenaçades (GELA, Study Group on Endangered Languages) research group. Their research interests include language revitalization, linguistic diversity and language ideologies. Their work has appeared in journals such as $\mathrm{xxxxx}, \mathrm{xxxx}$ and has been published in various books such as $\mathrm{xxxx}, \mathrm{xxxx}, \mathrm{xxxx}$.

\section{References}

Baker, C. (1992). Attitudes and Language. Clevedon: Multilingual Matters.

Barrieras, M., \& Monrós, E. (2005). Les llengües a Catalunya [Languages in Catalonia]. In M. C. Junyent (Ed.), Les llengües a Cataluny: Quantes llengües s'hi parlen? [Languages in Catalonia: How many languages are spoken?] (pp. 15-40) Barcelona: Octaedro.

Besnier, N. (1990). Language and affect. Annual Review of Anthropology, 19, 419-451.

Bohner, G., \& Dickel, N. (2011). Attitudes and Attitude Change. Annual Review of Psychology, 62, 391-417.

Boix, E. (1993). Triar no és trair: Identitat i llengua en els joves de Barcelona [Choosing is not betraying: Identity and language in youth in Barcelona]. Barcelona: Edicions 62.

Bruner, J. S. (1990). Acts of Meaning: Four Lectures on Mind and Culture. Cambridge, MA: Harvard University Press.

Bruner, J. S. (1996). The Culture of Education. Cambridge, MA: Harvard University Press.

Bucholtz, M., \& Hall, K. (2004). Language and identity. In A. Duranti (Ed.), A Companion to Linguistic Anthopology (pp. 369-394). Oxford: Blackwell.

Eckert, P. (1983). The Paradox of Regional Language Movements. Journal of Multilingual and Multicultural Development, 4, 289-300.

Edwards, J. (1992). Sociopolitical aspects of language maintenance and loss: towards a typology of minority language situations. In W. Fase, K. Jaspaert, \& S. Kroon (Eds.), Maintenance and Loss of Minority Languages (pp. 37-54). Amsterdam: John Benjamins.

Fishman, J. A. (1972). The Sociology of Language: An Interdisciplinary Social Science Approach to Language in Society. Rowley, MA: Newbury House.

Fishman, J. A. (1999). The new linguistic order. Foreign Policy, 1, 26-40. 
Gal, S. (1978). Peasant men can’t get wives: Language change and sex roles in a bilingual community. Language in Society, 7, 1-16.

Gardner, R. C., \& Lambert, W. E. (1972). Attitudes and Motivation in Second-Language Learning. Rowley, MA: Newbury House.

Gardner, R. C. (1985). Social Psychology and Second Language Learning: The Role of Attitudes and Motivation. London: Arnold.

Glasman, L. R., \& Albarracín, D. (2006). Forming attitudes that predict future behavior: a metaanalysis of the attitude-behavior relation. Psychological Bulletin, 132, 778-822.

Grenoble, L. A., \& Whaley, L. J. (1998). Toward a typology of language endangerment. In L. A. Grenoble, \& L. J. Whaley (Eds.), Endangered Languages: Current Issues and Future Prospects (pp. 22-54). Cambridge: Cambridge University Press.

Huguet, A., \& Janés, J. (2008). Mother tongue as a determining variable in language attitudes. The case of immigrant Latin American students in Spain. Language and Intercultural communication, 8, 246-260.

Institut d'Estadística de Catalunya. (2013). Enquesta d'usos lingüístics de la població 2013 [Survey of population language use in 2013]. Barcelona: Generalitat de Catalunya. Retrieved from http://www.idescat.cat/pub/?id=eulp.

Irvine, J. T., \& Gal, S. (2000). Language ideology and linguistic differentiation. In P. V. Kroskrity (Ed.), Regimes of Language: Ideologies, polities, and identities (pp. 35-84). Santa Fe: School of American Research Press.

Jaffe, A. M. (1999). Ideologies in action: Language politics on Corsica. Berlin: Mouton de Gruyter.

Junyent, M. C., Monrós, E., Fidalgo, M., Cortès-Colomé, M., Comellas, P., \& Barrieras, M. (2011). Canvi de representacions lingüístiques de parlants al·loglots per contacte amb la situació lingüística catalana. [Change of linguistic representations by immigrant alloglots due to contact with the Catalan linguistic situation]. Recerca i immigració [Research and immigration] (Vol. 3, pp. 93-108). Barcelona: Generalitat de Catalunya.

Kasbarian, J. M. (1997). Langue minorée et langue minoritaire. In M. L. Moreau (Ed.), Sociolinguistique. Concepts de base (pp. 185-188). Bruxelles: Mardaga.

Kramsch, C. (2006). The Multilingual Subject. International Journal of Applied Linguistics, 16, $97-110$.

Kroskrity, P. V. (2004). Language ideologies. In A. Duranti (Ed.), A Companion to Linguistic Anthropology (pp. 496-517). Oxford: Blackwell.

Lasagabaster, D. (2003). Trilingüismo en la enseñanza: Actitudes hacia la lengua minoritaria, la mayoritaria y la extrangera [Trilingualism in Teaching: Attitudes Towards the Minority, Majority and Foreign Languages]. Lleida: Milenio. 
Lasagabaster, D., \& Huguet, A. (2007). Multilingualism in European Bilingual Contexts.

Clevedon, UK: Multilingual Matters.

McEwan-Fujita, E. (2010). Ideology, affect, and socialization in language shift and revitalization: The experiences of adults learning Gaelic in the Western Isles of Scotland. Language in Society, 39, 27-64.

Nettle, D., \& Romaine, S. (2000). Vanishing voices. The extinction of the world's languages. Oxford: Oxford University Press.

Newcombe, L. P. (2007). Social context and fluency in L2 learners: The case of Wales. Clevedon, UK: Multilingual Matters.

Ochs, E. (1996). Linguistic resources for socializing humanity. In J. J. Gumperz \& S. C. Levinson (Eds.), Rethinking linguistic relativity (pp. 407-437). Cambridge, UK: Cambridge University Press.

Ochs, E., \& Schieffelin, B. B. (1989). Language has a heart. Text, 9, 7-25.

Pütz, M. (Ed.). (1994). Language Contact and Language Conflict. Amsterdam: John Benjamins.

Spencer-Rodgers, J., \& McGovern, T. (2002). Attitudes toward the culturally different: The role of intercultural communication barriers, affective responses, consensual stereotypes, and perceived threat. International Journal of Intercultural Relations, 26, 609-631.

Sasse, H. J. (1992). Theory of language death. In M. Brenzinger (Ed.). Language death: factual and theoretical explorations with special reference to East Africa (pp. 7-29). Berlin: Mouton de Gruyter.

Stephan, W. G., \& Stephan, C. W. (1996). Predicting prejudice. International Journal of Intercultural Relations, 20, 409-426.

Timm, L. A. (2001). Transforming Breton: A Case Study in Multiply Conflicting Language Ideologies. Texas Linguistic Forum, 44, 447-461.

Vila, F. X., \& Galindo, M. (2012). Sobre la història i l'extensió de la norma de convergència lingüística a Catalunya [On the history and extent of accommodation norm in Catalonia]. In F. X. Vila (Ed.) Posar-hi la base: Usos i aprenentatges lingüístics en el domini català [Placing the base: Uses and language learning in the Catalan domain] (pp. 31-45). Barcelona: Institut d'Estudis Catalans.

Wertsch, J. V. (1985). Vygotsky and the social formation of mind. Cambridge, MA: Harvard University Press.

Woolard, K. A. (1989). Double Talk: Bilingualism and the Politics of Ethnicity in Catalonia. Stanford: Stanford University Press.

Woolard, K. A. (2008). Language and Identity Choice in Catalonia: The Interplay of Contrasting Ideologies of Linguistic Authority. Retrieved from http://www.itintransit.eu/articles/language-and-identity-choice-catalonia-interplay-contrastingideologies-linguistic-authorit. 